Article

\title{
Radical Copolymerization Kinetics of Bio-Renewable Butyrolactone Monomer in Aqueous Solution
}

\author{
Sharmaine B. Luk and Robin A. Hutchinson * \\ Department of Chemical Engineering, Queen's University, 19 Division St, Kingston, ON K7L3N6, Canada; \\ sharmaine.luk@queensu.ca \\ * Correspondence: robin.hutchinson@queensu.ca; Tel.: +1-613-533-3097
}

Received: 6 September 2017; Accepted: 27 September 2017; Published: 1 October 2017

\begin{abstract}
The radical copolymerization kinetics of acrylamide (AM) and the water-soluble monomer sodium 4-hydroxy-4-methyl-2-methylene butanoate (SHMeMB), formed by saponification of the bio-sourced monomer $\gamma$-methyl- $\alpha$-methylene- $\gamma$-butyrolactone (MeMBL), are investigated to explain the previously reported slow rates of reaction during synthesis of superabsorbent hydrogels. Limiting conversions were observed to decrease with increased temperature during SHMeMB homopolymerization, suggesting that polymerization rate is limited by depropagation. Comonomer composition drift also increased with temperature, with more AM incorporated into the copolymer due to SHMeMB depropagation. Using previous estimates for the SHMeMB propagation rate coefficient, the conversion profiles were used to estimate rate coefficients for depropagation and termination $\left(k_{\mathrm{t}}\right)$. The estimate for $k_{\mathrm{t}, \mathrm{SHM}} \mathrm{MB}$ was found to be of the same order of magnitude as that recently reported for sodium methacrylate, with the averaged copolymerization termination rate coefficient dominated by the presence of SHMeMB in the system. In addition, it was found that depropagation still controlled the SHMeMB polymerization rate at elevated temperatures in the presence of added salt.
\end{abstract}

Keywords: bio-renewable; depropagation; ionic strength; parameter estimation

\section{Introduction}

Water-soluble polymers are used extensively in personal products for hair care [1] and detergents [2], with crosslinked materials utilized as absorbent hydrogels in diapers or feminine products [3]. Other applications include drug delivery [4], flocculation for water recovery in oil sand tailings [5], and metal ion recovery [6]. The bio-derived monomers $\alpha$-methylene- $\gamma$-butyrolactone (MBL) and $\gamma$-methyl- $\alpha$-methylene- $\gamma$-butyrolactone (MeMBL) have previously been homopolymerized $[7,8]$ and copolymerized with styrene (ST) and methyl methacrylate (MMA) $[9,10]$, but in bulk or organic solution. Recently, Kollár et al. demonstrated that MBL could be saponified with sodium hydroxide $(\mathrm{NaOH})$ to make a water-soluble monomer, sodium 4-hydroxy-2-methylene butanoate (SHMB), that was copolymerized with acrylamide (AM) and crosslinker to make superabsorbent hydrogels that exhibited superior water absorbency compared to conventional sodium acrylate:AM materials [11]. In an extension of that work, MeMBL was saponified to sodium 4-hydroxy-4-methyl-2-methylene butanoate (SHMeMB) (see Scheme 1), which was copolymerized with AM and crosslinker to make similar superabsorbent materials [12]. 


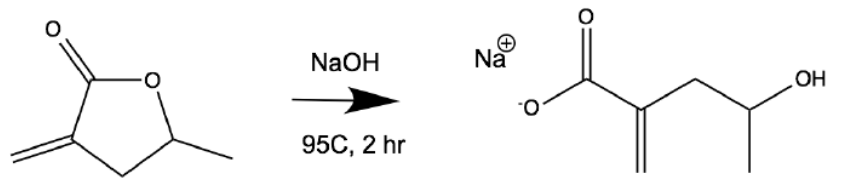

Scheme 1. Saponification of $\gamma$-methyl- $\alpha$-methylene- $\gamma$-butyrolactone (MeMBL) using $\mathrm{NaOH}$ in water for $2 \mathrm{~h}$ at $95{ }^{\circ} \mathrm{C}$ to form sodium 4-hydroxy-4-methyl-2-methylene butanoate (SHMeMB).

The SHMeMB:AM hydrogels showed higher water absorbency than SHMB:AM hydrogels, a finding attributed to changes in crosslink density caused by reactivity differences between the two systems [12]. Conversion profiles obtained from in situ NMR showed very slow homopolymerization rates of both SHMB and SHMeMB, and a lowered copolymerization rate for SHMeMB:AM compared to SHMB:AM. The lower reactivity of SHMeMB:AM was partially attributed to differences in the system reactivity ratios, estimated as $r_{\mathrm{SHM}} \mathrm{MB}=0.12-0.17$ and $r_{\mathrm{AM}}=0.95-1.10$ for SHMeMB:AM [12] compared to $r_{\mathrm{SHMB}}=0.35 \pm 0.15$ and $r_{\mathrm{AM}}=1.42 \pm 0.40$ for SHMB:AM [11]. Using pulsed-laser polymerization coupled with aqueous-phase size exclusion chromatography (PLP-SEC), the rate of radical chain growth of SHMB:AM copolymers was found to be twice that of SHMeMB:AM under identical conditions. It was not possible, however, to find suitable experimental conditions to directly study SHMeMB homopropagation by the PLP technique. Thus, the copolymerization results were extrapolated to provide the first estimates of the homopropagation rate coefficients $\left(k_{\mathrm{p}}\right)$, with very low values of 165 and $25 \mathrm{~L} \cdot \mathrm{mol}^{-1} \cdot \mathrm{s}^{-1}$, estimated at $60^{\circ} \mathrm{C}$ in aqueous solution for SHMB and SHMeMB, respectively [12].

As both SHMB and SHMeMB are fully-ionized water-soluble monomers, their polymerization kinetics in aqueous solution are not well-understood. However, previous studies using PLP-SEC, the IUPAC recommended method for determining $k_{\mathrm{p}}$ [13], have examined the radical polymerization behavior of other water-soluble monomers, including non-ionized to fully ionized acrylic and methacrylic acids [14-17] and acrylamide [18]. It is now known that the polymerization kinetics of these monomers in water differ significantly from those of the same monomers in organic solvents, with the $k_{\mathrm{p}}$ values of non-ionized acrylic acid and methacrylic acid significantly higher in water than in methanol and dimethyl sulfoxide (DMSO) [19]. In addition, the kinetics are greatly affected by monomer concentration in aqueous solution, as studied for acrylic acid [16], methacrylic acid [17], and acrylamide [20]. The dependence of $k_{\mathrm{p}}$ on monomer concentration was attributed to the hydrogen-bonding effects between water, monomer, and radical species. Although $k_{\mathrm{p}}$ is dependent on monomer concentration, it was found that the reactivity ratios of AM and non-ionized acrylic acid copolymerization were constant with concentration [21], although the values are dependent on monomer concentration and ionic strength for copolymerization of AM with fully-ionized AA [22,23]. It should be noted that hydrogen-bonding effects are not only present in aqueous solution, but also influence the reactivity ratios of butyl methacrylate (BMA) and 2-hydroxyethyl acrylate (HEA) copolymerization in organic solution, as the relative reactivity of the two monomers is dependent on solvent choice [24].

Another kinetic mechanism important to this study is depropagation. For most radical polymerizations, the monomer addition to a growing macroradical (propagation) can be considered as an irreversible reaction. However, depropagation, the process by which a single monomer unit is released from the growing radical chain, occurs if there is steric hindrance near the radical site. Under these conditions, the propagation and depropagation mechanisms become a reversible reaction pair, with the relative rates (and hence overall rate of polymerization) a function of temperature and monomer concentration. Some monomers that are known to depropagate are BMA [25], itaconates [26], methyl ethacrylate [27], and $\alpha$-methyl styrene [28], all studied in organic solution. In the presence of appreciable rates of depropagation, the polymerization does not reach full monomer conversion and the reaction can also influence copolymer composition as well as rate, as seen for the radical copolymerization of methyl ethacrylate and styrene (MEA/ST) [29] and BMA/ST at elevated 
temperature [25]. It is interesting to note that $\alpha$-methylene- $\delta$-valerolactone (MVL), a monomer of similar structure to $\mathrm{MBL}$, has been shown to undergo depropagation, with a ceiling temperature of $83{ }^{\circ} \mathrm{C}$ [30]. Depropagation of MVL was attributed to its non-planar structure that hinders the radical center, while MBL does not depropagate as it is planar in structure.

In this publication, a series of studies were done to further elucidate the polymerization kinetics of SHMeMB homopolymerization and SHMeMB:AM copolymerization. Polymerizations were conducted at elevated temperatures $\left(60\right.$ to $\left.90^{\circ} \mathrm{C}\right)$ to explore the importance of depropagation, using in situ NMR spectroscopy to track monomer conversions. In addition, homopolymerizations were done in the presence of added salt to observe whether the changes in the polymerization rate are similar to those reported for fully ionized acrylic acid (sodium acrylate, NaAA) [31,32] and methacrylic acid (sodium methacrylate, NaMAA) [33]. The homopolymerization conversion profiles were used to estimate the rate coefficients for termination $\left(k_{\mathrm{t}}\right)$ and depropagation $\left(k_{\mathrm{dep}}\right)$, using the parameter estimation capabilities in the PREDICI ${ }^{\circledR}$ software package [34]. Ultimately, the estimated parameters from SHMeMB homopolymerization were implemented in a kinetic model developed to represent SHMeMB:AM copolymerization behavior.

\section{Materials and Methods}

\subsection{Materials}

The following chemicals were purchased from Sigma-Aldrich, Canada and used as received: acrylamide (AM, >98\%), $N, N^{\prime}$-methylenebis(acrylamide) (BIS, 99\%), 2,2'-azobis(2-methylpropionamidine) dihydrochloride (V-50 initiator, 97\%), and sodium hydroxide $(\mathrm{NaOH},>97 \%)$. 2,2'-Azobis[2-methyl-N-(2-hydroxyethyl)propionamide] (V-86 initiator) was purchased from Wako Pure Chemicals Ltd., USA. Deuterated water $\left(\mathrm{D}_{2} \mathrm{O}, 99.8 \% \mathrm{D}\right)$ and hydrochloric acid $(\mathrm{HCl}, 36.5 \% w / w)$ were purchased from Fisher Scientific, Canada and the $\gamma$-methyl- $\alpha$-methylene- $\gamma$-butyrolactone (MeMBL, >97\%) was provided by DuPont Central Research Laboratories.

\subsection{Ring-Opening Saponfication of MeMBL}

The saponification of MeMBL followed the same procedure as in previous studies [11,12]. For $1 \mathrm{~g}$ of MeMBL, $10 \mathrm{~mol} \%$ excess of $\mathrm{NaOH}$ was measured and dissolved in $1 \mathrm{~g}$ of $\mathrm{D}_{2} \mathrm{O}$ in a small vial with a stir-bar. The saponification reaction took place in an oil bath at $95^{\circ} \mathrm{C}$ for $2 \mathrm{~h}$, after which the solution was cooled to room temperature and $1 \mathrm{M} \mathrm{HCl}$ was added until a $\mathrm{pH}$ of 7 was reached. The SHMeMB mixture was then diluted with $\mathrm{D}_{2} \mathrm{O}$ to a final monomer concentration of $40 \mathrm{wt} \%$ (including mass of sodium ions). This stock solution was mixed with other components to achieve desired concentrations for the in situ NMR studies. The structure of MeMBL was confirmed by NMR, and ring structures were confirmed to be completely opened to make SHMeMB [12].

\subsection{Preparation for In Situ NMR}

The in situ NMR method was used to measure the overall monomer conversion profiles, as well as the variation of monomer and polymer composition with conversion, following procedures described by Preusser and Hutchinson [21]. Near-isothermal conditions for the experiments can be assumed based upon the slow rate of polymerization compared to other systems analyzed in the same setup [21]. Copolymerizations were conducted at 3:7 and 4:6 SHMeMB:AM initial molar ratios and $15 \mathrm{wt} \%$ monomer concentration in $\mathrm{D}_{2} \mathrm{O}$, with initiator content specified as a weight percent of the total mixture (monomers $+\mathrm{D}_{2} \mathrm{O}$ ). Homopolymerizations were done at 15 and $30 \mathrm{wt} \%$ monomer concentration in $\mathrm{D}_{2} \mathrm{O}$, and salt was added to the monomer mixture relative to the SHMeMB molar amounts. While the preparation of the SHMeMB monomer added slightly to the ionic strength of the solution (addition of $10 \mathrm{~mol} \%$ excess $\mathrm{NaOH}$ followed by neutralization with $\mathrm{HCl}$ ), this contribution was not considered when reporting salt concentrations in the discussion section. 
Overall conversion $X(t)$ was calculated from the decrease in monomer peak integrations relative to the HOD reference peak (residual solvent peak from $\mathrm{D}_{2} \mathrm{O}$ at $4.8 \mathrm{ppm}$ ), and individual conversions of $\mathrm{SHMeMB}$ and $\mathrm{AM}$ were used to calculate $\mathrm{SHMeMB}$ monomer $\left(f_{\mathrm{SHMeMB}}\right)$ and polymer mole fractions $\left(F_{\mathrm{SHMeMB}}\right)$, as detailed in our previous study [12].

\subsection{Kinetic Parameters for PREDICI Parameter Estimation}

The parameter estimations for SHMeMB homopolymerizations and SHMeMB:AM copolymerizations were done using PREDICI [34], based on the reaction mechanisms listed in Table 1. For SHMeMB:AM copolymerizations, $k_{\mathrm{t}}$ represents an averaged value for all three termination mechanisms; as will be discussed, the values were estimated from individual experimental monomer conversion profiles to provide a perspective on how the averaged rate coefficient varies with monomer composition. As the termination rate is dominated by the large fraction of SHMeMB radicals in the system, the reaction is assumed to occur solely by disproportionation due to their hindered structure; this assumption does not impact the $k_{\mathrm{t}}$ values estimated from the conversion profiles. Depropagation was also considered in the model, based on the assumption that the reaction occurs only if both the penultimate and terminal monomer units of the growing radical chain are SHMeMB, as captured by the probability factor $p_{11}$ [25].

Table 1. Reaction mechanisms for the copolymerization of SHMeMB and acrylamide (AM).

\begin{tabular}{cl}
\hline Reaction Mechanisms & \\
\hline Initiator decomposition & $I \stackrel{k_{\mathrm{d}}}{\rightarrow} 2 f R_{o}^{*}$ \\
Initiation & $R_{0}^{*}+S H M e M B \stackrel{k_{\mathrm{p} 1,1}}{\rightarrow} S H M e M B_{1}^{*}$ \\
& $R_{0}^{*}+A M \stackrel{k_{\mathrm{p} 2,2}}{\rightarrow} A M_{1}^{*}$ \\
& $S H M e M B_{\mathrm{n}}^{*}+S H M e M B \stackrel{k_{\mathrm{p} 1,1}}{\rightarrow} S H M e M B_{\mathrm{n}+1}^{*}$ \\
& $S H M e M B_{\mathrm{n}}^{*}+A M \stackrel{k_{\mathrm{p} 1,2}}{\rightarrow} A M_{\mathrm{n}+1}^{*}$ \\
& $A M_{\mathrm{n}}^{*}+S H M e M B \stackrel{k_{\mathrm{p} 2,1}}{\rightarrow} S H M e M B_{\mathrm{n}+1}^{*}$ \\
& $A M_{\mathrm{n}}^{*}+A M \stackrel{k_{\mathrm{p} 2,2}}{\rightarrow} A M_{\mathrm{n}+1}^{*}$ \\
& $S H M e M B_{\mathrm{n}}^{*}+S H M e M B_{\mathrm{m}}^{*} \stackrel{k_{\mathrm{f}}}{\rightarrow} P_{\mathrm{n}}+P_{\mathrm{m}}$ \\
& $A M_{\mathrm{n}}^{*}+S H M e M B_{\mathrm{m}}^{*} \stackrel{k_{\mathrm{b}}}{\rightarrow} P_{\mathrm{n}}+P_{\mathrm{m}}$ \\
& $A M_{\mathrm{n}}^{*}+A M_{\mathrm{m}}^{*} \stackrel{k_{\mathrm{b}}}{\rightarrow} P_{\mathrm{n}}+P_{\mathrm{m}}$ \\
& $S H M e M B_{\mathrm{n}}^{*} \stackrel{p_{11} k_{\mathrm{dep}}}{\rightarrow} S H M e M B_{\mathrm{n}-1}^{*}+S H M e M B$ \\
\hline
\end{tabular}

The known rate coefficients (initiator decomposition, homopropagation, and reactivity ratios) are shown in Table 2. The initiator efficiency $(f)$ of V-50 was assumed to be 0.8 , and for V-86 it was assumed to be 0.38 , as determined in a previous study [35]. The propagation rate expression for AM homopolymerization was determined [18] and modelled [20] previously as a function of both monomer concentration and temperature, yielding a $k_{\mathrm{p}, \mathrm{AM}}$ value of $86,000 \mathrm{~L} \cdot \mathrm{mol}^{-1} \cdot \mathrm{s}^{-1}$ for $15 \mathrm{wt} \%$ $\mathrm{AM}$ in aqueous solution at $50^{\circ} \mathrm{C}$. Although AM concentration changes with SHMeMB:AM comonomer composition (keeping total monomer content at $15 \mathrm{wt} \%$ ), the value of $k_{\mathrm{p}, \mathrm{AM}}$ in the model was kept constant. This assumption is reasonable, as $k_{\mathrm{p}}{ }^{\text {cop }}$ is dominated by the low value of $k_{\mathrm{p}, \mathrm{SHMeMB}}$ and not sensitive to small changes in $k_{\mathrm{p}, \mathrm{AM}}$. As shown in Table $\mathrm{S} 1$ in the supporting information, $k_{\mathrm{p}, \mathrm{AM}}$ values were calculated at a different total AM wt \% (while maintaining $15 \mathrm{wt} \%$ monomer concentration) and the estimated values for $k_{\mathrm{t}}$ remained the same. The PLP-SEC estimate for $k_{\mathrm{p}, \mathrm{SHMeMB}}$, obtained at $60{ }^{\circ} \mathrm{C}$ and $15 \mathrm{wt} \%$ monomer in the previous study [12], was used in this work. 
Table 2. Rate expressions for known kinetic coefficients used in model of SHMeMB:AM copolymerization.

\begin{tabular}{ccc}
\hline Reaction & Rate Expression & References \\
\hline Decomposition of V-50 & $k_{\mathrm{d}}=9.385 \times 10^{14} \exp (-14,890 / T(\mathrm{~K}))$ & {$[\mathrm{f}=0.8$} \\
Decomposition of V-86 & $k_{\mathrm{d}}=1.24 \times 10^{13} \exp (-14,800 / T(\mathrm{~K}))$ & $\mathrm{f}=0.38$ \\
& $k_{\mathrm{p}}^{0}=9.5 \times 10^{7} \exp (-2189 / T(\mathrm{~K}))$ & \\
Propagation of AM & $k_{\mathrm{p}}=k_{\mathrm{p}}^{0} \exp \left(-0.01 c_{\mathrm{AM}}(0.0016 \mathrm{~T}+1.015)\right)$ & {$[18]$} \\
Propagation of SHMeMB & $k_{\mathrm{p}}=25 \mathrm{~L} \cdot \mathrm{mol}^{-1} \cdot \mathrm{s}^{-1}$ & {$[12]$} \\
Reactivity ratios at $\mathbf{5 0}{ }^{\circ} \mathbf{C}$ & $r_{\mathrm{AM}}=k_{\mathrm{p} 2,2} / k_{\mathrm{p} 2,1}=0.95 \pm 0.01$ & {$[12]$} \\
\hline
\end{tabular}

\section{Results and Discussion}

\subsection{Copolymerization of SHMeMB:AM at Different Temperatures}

In the previous study, in situ batch copolymerizations of SHMeMB and $\mathrm{AM}$ at $50{ }^{\circ} \mathrm{C}$ over a wide range of compositions (initial mole fraction of $\mathrm{SHMeMB}, f_{\mathrm{SHMeMB}}$, between 0.1 and 0.8 ) were used to estimate the reactivity ratios of the system summarized in Table 2 . In this work, the study was extended to higher temperatures. Conversion profiles measured for experiments with V-50 initiator at an initial monomer content of $15 \mathrm{wt} \%$ and SHMeMB:AM molar ratios of $3: 7\left(50-80^{\circ} \mathrm{C}\right)$ and 4:6 $\left(50-70{ }^{\circ} \mathrm{C}\right)$ are shown in Figure 1. It is evident that the initial rate of polymerization increases with temperature, as expected due to the accelerated radical production rate as well as the increased $k_{\mathrm{p}}$ values. However, monomer conversion plateaus at less than $100 \%$ at the higher temperatures. This limiting conversion does not result from initiator depletion, as $27 \%$ of the V-50 remains after $3 \mathrm{~h}$ at $70^{\circ} \mathrm{C}$, based on literature values for $\mathrm{V}-50$ decomposition kinetics. The conversion plateau occurs at a lower conversion as the initial fraction of SHMeMB is increased, as seen by comparing the profiles for 3:7 and 4:6 SHMeMB:AM after $3 \mathrm{~h}$. Thus, the presence of SHMeMB not only affects the initial rate of polymerization, but also causes the copolymerization rate to significantly slow down as higher conversions are reached at the higher temperatures.
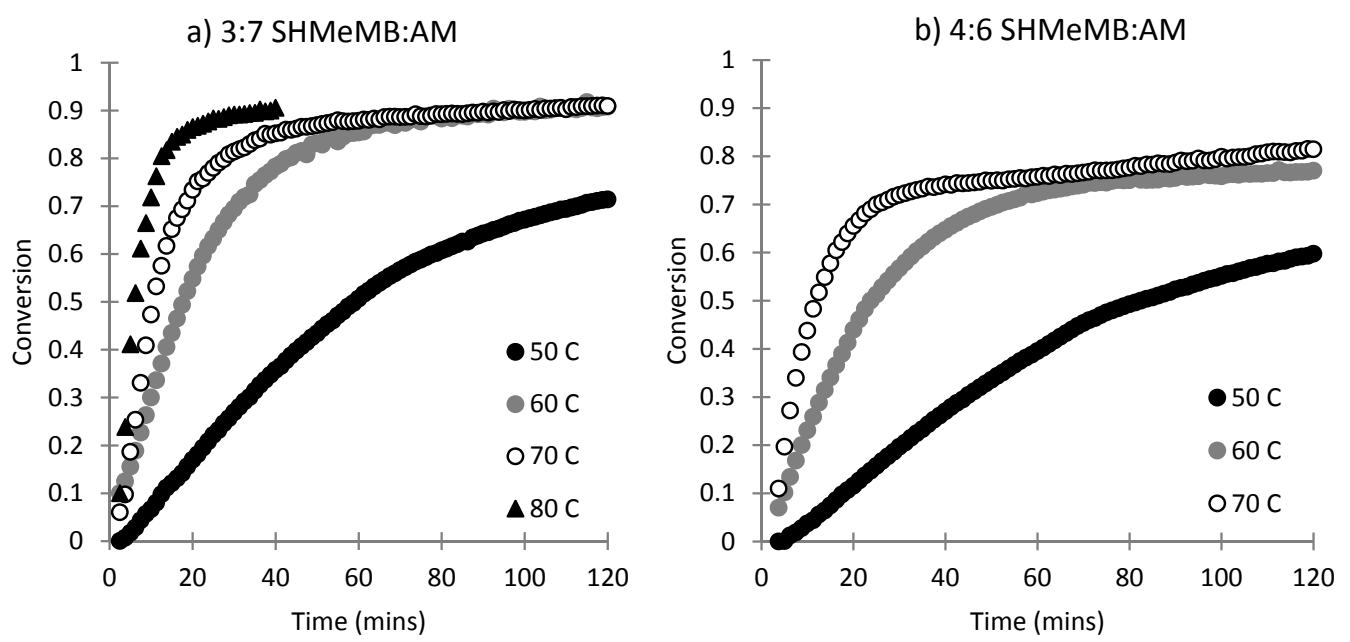

Figure 1. Overall monomer conversion profiles for copolymerizations at (a) 3:7 and (b) 4:6 initial SHMeMB:AM molar ratios at varying temperatures with $15 \mathrm{wt} \%$ monomer and $0.5 \mathrm{wt} \% \mathrm{~V}-50$.

Individual monomer concentration profiles of SHMeMB and $\mathrm{AM}$ at 50,60 , and $70^{\circ} \mathrm{C}$ are presented as Figure $\mathrm{S} 1$ in the supporting information. The plots show that the rate of SHMeMB consumption becomes very slow at the lowered SHMeMB concentrations reached later in the reactions, while the 
consumption of AM continues. This behavior becomes more evident at higher temperatures and increased SHMeMB content, under which conditions the absolute concentration of AM decreases to values below that of SHMeMB, despite its higher initial value. The limiting SHMeMB conversions suggest that depropagation of SHMeMB monomer may be occurring, leading to a significantly decreased rate of polymerization as AM is consumed.

To further explore this possibility, the comonomer composition drifts with conversion at different temperatures are plotted in Figure 2; the curves are normalized by the initial fraction of SHMeMB in the mixture to provide a better comparison by eliminating slight variations in the initial compositions. If SHMeMB depropagation is important, the value of $f_{\text {SHMeMB }}$ would increase more significantly with conversion as temperature is increased due to decreased incorporation of SHMeMB under conditions that favour depropagation, as seen in studies of MEA/ST [29] and BMA/ST [25]. As shown in Figure 2, this behavior is indeed observed for the SHMeMB:AM system as temperature increased from 50 to $80^{\circ} \mathrm{C}$. At higher conversions where monomer concentrations are low, the influence of depropagation on $\mathrm{SHMeMB}$ consumption becomes more prominent. The reaction temperature was further increased to $90^{\circ} \mathrm{C}$ using a different initiator, V-86, as it has a slower rate of decomposition. At $90^{\circ} \mathrm{C}$, there was further deviation of the drift in $f_{\mathrm{SHMeMB}}$ with conversion compared to $50^{\circ} \mathrm{C}$. Reactions with $\mathrm{V}-50$ and $\mathrm{V}-86$ were conducted at the same temperatures to verify that composition drift was consistent using both initiators (see Figure S2).
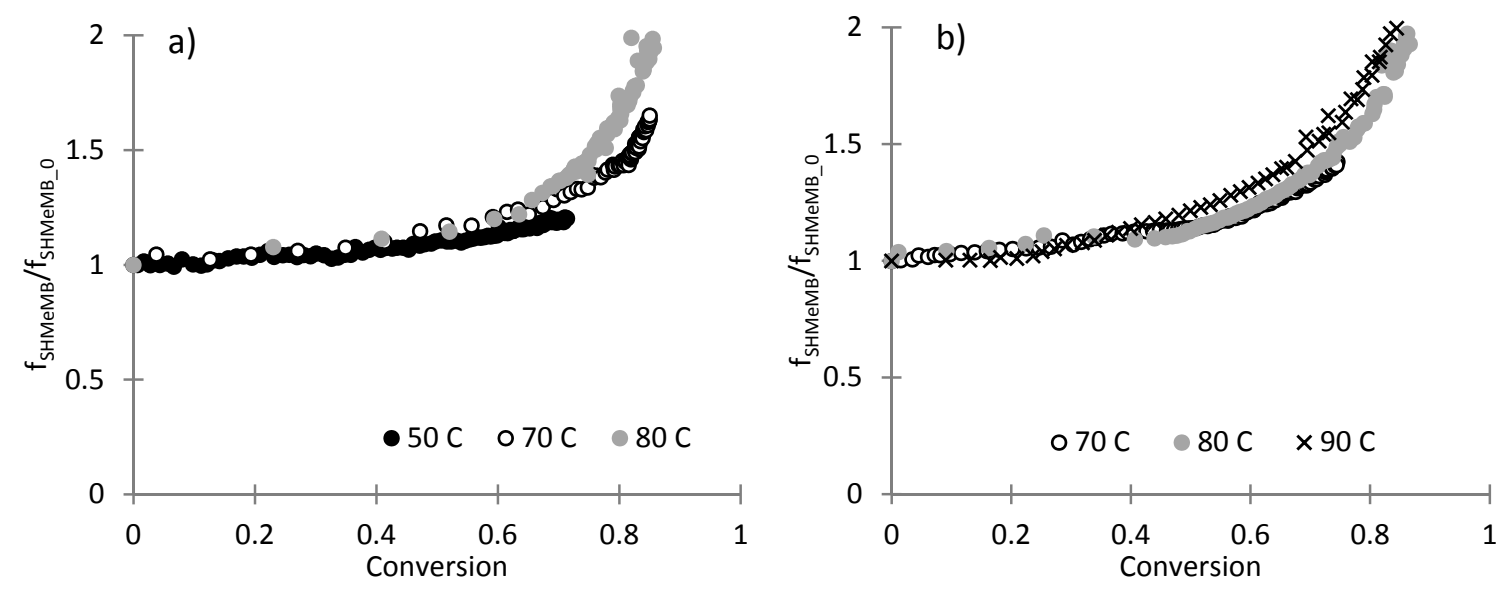

Figure 2. Monomer composition drift with conversion for copolymerization with an initial 3:7 SHMeMB:AM molar ratio, $15 \mathrm{wt} \%$ monomer and (a) $0.5 \mathrm{wt} \%$ V-50 initiator, or (b) $1.67 \mathrm{wt} \%$ V-86 initiator at varying temperatures $\left(90{ }^{\circ} \mathrm{C}\right.$ experiment was conducted with $\left.0.5 \mathrm{wt} \% \mathrm{~V}-86\right)$. Monomer composition was normalized by initial monomer composition to eliminate the influence of slight variations in the comonomer mixture composition.

As a first step to understanding this behavior, monomer composition drifts measured with 3:7 molar ratio of SHMeMB:AM copolymerizations at 70 and $80^{\circ} \mathrm{C}$ were fitted to provide reactivity ratio estimates, with results shown in Figure 3. Two methods were used to fit the experimental data: the first uses the previously determined $r_{\mathrm{AM}}=0.951$ so that only one parameter $\left(r_{\mathrm{SHMeMB}}\right)$ was estimated, as depropagation should only influence the addition rate of a SHMeMB monomer to a SHMeMB radical, and thus the effective value of $r_{\mathrm{SHMeMB}}$. For the second fitting, both parameters, $r_{\mathrm{AM}}$ and $r_{\mathrm{SHMeMB}}$, were estimated simultaneously. 

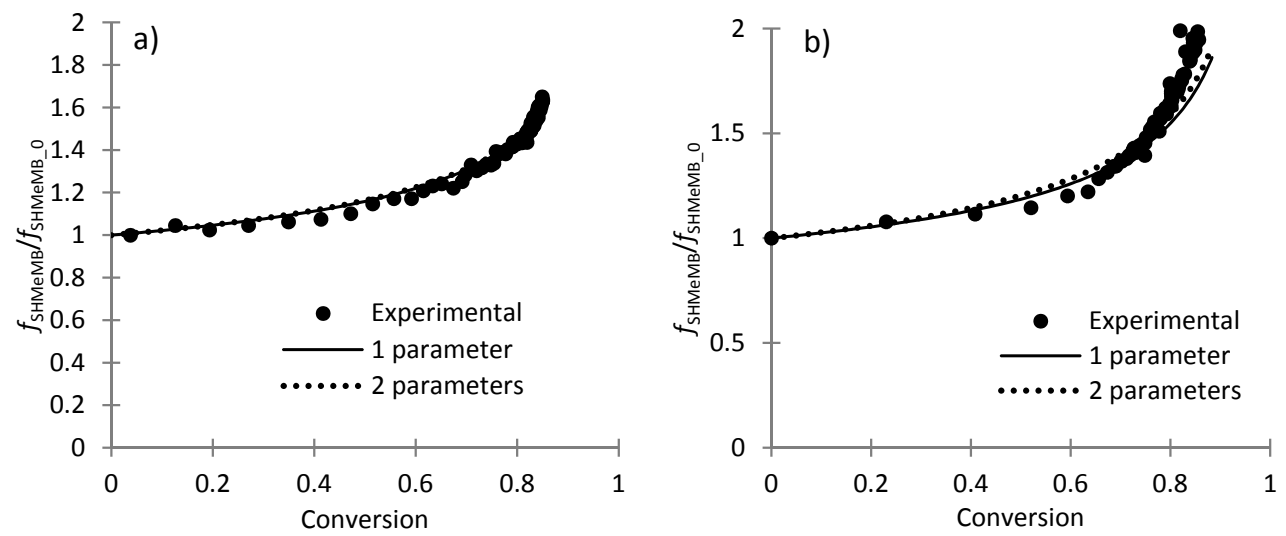

Figure 3. Monomer composition drift for copolymerizations of 3:7 molar ratio of SHMeMB:AM with $15 \mathrm{wt} \%$ monomer and $0.5 \mathrm{wt} \% \mathrm{~V}-50$ at (a) 70 and (b) $80{ }^{\circ} \mathrm{C}$. The solid line represents parameter estimation with $r_{\mathrm{AM}}$ fixed at 0.951 (best-fit value at $50{ }^{\circ} \mathrm{C}$ ), and the dotted line represents parameter estimation to determine both $r_{\mathrm{AM}}$ and $r_{\mathrm{SHMeMB}}$, with values summarized in Table 3.

As shown by Figure 3, both methods gave good representations to the experimental data, but with drastically different estimates for $r_{\mathrm{SHMeMB}}$, as summarized in Table 3 . The terminal model reactivity ratio of monomer one $\left(r_{1}\right)$ is defined by Equation (1), where $k_{\mathrm{p}, 11}$ is the homopropagation rate coefficient for addition of monomer one to a monomer one radical and $k_{\mathrm{p}, 12}$ is the cross-propagation rate coefficient for the addition of monomer two to a monomer one radical.

$$
r_{1}=\frac{k_{\mathrm{p}, 11}}{k_{\mathrm{p}, 12}}
$$

When the value of $r_{\mathrm{AM}}$ was fixed at 0.951 , the parameter estimation forces $r_{\mathrm{SHMeMB}}$ to approach zero, indicating that AM monomer addition is greatly favoured over SHMeMB addition to a SHMeMB terminal radical. Estimating $r_{\mathrm{SHMeMB}}$ and $r_{\mathrm{AM}}$ simultaneously at $70{ }^{\circ} \mathrm{C}$ gave an $r_{\mathrm{AM}}$ value that was close to the value determined at $50{ }^{\circ} \mathrm{C}$, and lowered the $r_{\mathrm{SHMeMB}}$ value to 0.120 (from 0.169 at $50{ }^{\circ} \mathrm{C}$ ). At $80^{\circ} \mathrm{C}, r_{\mathrm{SHM}}$ MB decreased to an even lower value of 0.046 due to more prominent depropagation effects at higher temperatures. While these values seem plausible, the uncertainty in the estimates are large. Nonetheless, they are consistent with the expectations of depropagation.

Table 3. Reactivity ratios estimates from copolymerization of 3:7 molar ratio of SHMeMB:AM with $15 \mathrm{wt} \%$ monomer and $0.5 \mathrm{wt} \% \mathrm{~V}-50$ at 70 and $80^{\circ} \mathrm{C}$. The "one parameter" method estimates $r_{\mathrm{SHM}} \mathrm{MBB}$ with $r_{\mathrm{AM}}$ fixed at 0.951 , and the "two parameter" method estimates both $r_{\mathrm{AM}}$ and $r_{\mathrm{SHMeMB}}$.

\begin{tabular}{ccccc}
\hline & \multicolumn{2}{c}{$7 \mathbf{0}^{\circ} \mathbf{C}$} & \multicolumn{2}{c}{$80^{\circ} \mathbf{C}$} \\
\cline { 2 - 5 } & 1 Parameter & 2 Parameters & 1 Parameter & 2 Parameters \\
\hline$r_{\mathrm{SHMeMB}}$ & $0.005 \pm 0.008$ & $0.12 \pm 0.22$ & $7 \times 10^{-6} \pm 7 \times 10^{-3}$ & $0.05 \pm 0.17$ \\
$r_{\mathrm{AM}}$ & - & $1.04 \pm 0.17$ & - & $1.06 \pm 0.21$ \\
\hline
\end{tabular}

It is important to note that the parameter estimation fits the reactivity ratios based on the terminal model (i.e., no depropagation), assuming that the value of $k_{\mathrm{p}, \mathrm{SHMeMB}}$ remains constant with conversion. In the case of depropagation, the $k_{\mathrm{p}, 11}$ value should be considered as an effective value, $k_{\mathrm{p}}{ }^{\text {eff }}$, dependent on $k_{\mathrm{p}}, k_{\mathrm{dep}}$ and monomer concentration [M] as shown in Equation (2) [26], such that $r_{\mathrm{SHMeMB}}$ would change with conversion.

$$
k_{\mathrm{p}}^{\text {eff }}=k_{\mathrm{p}}-\frac{k_{\mathrm{dep}}}{[M]}
$$

Thus, the conversion profiles for SHMeMB homopolymerizations are first used to estimate $k_{\text {dep }}$ before returning to analysis of the copolymerization system. 


\subsection{Homopolymerization Kinetics of SHMeMB}

To investigate depropagation kinetics further, the in situ NMR technique was used to study homopolymerization of SHMeMB at increased temperature and initiator content $\left(75^{\circ} \mathrm{C}\right.$ and $1 \mathrm{wt} \%$ $\mathrm{V}-86)$, with reaction times $(14 \mathrm{~h})$ considerably extended compared to copolymerizations. The conversion profiles, shown in Figure 4, were the same for both initial monomer concentrations (15 and $30 \mathrm{wt} \%$ ), consistent with reports that monomer concentration did not have a large effect on $k_{\mathrm{p}}$ for other fully ionized monomers such as NaMAA [17]. However, no difference in the final conversions is seen between the two experiments, indicating that monomer concentrations were not yet approaching the equilibrium values at which depropagation would cause a difference in limiting conversion.

The possible effects of depropagation on the homopolymerization of SHMeMB were investigated at higher temperatures. In Figure 4, the initial rate of polymerization is seen to be faster at $90{ }^{\circ} \mathrm{C}$ than at $75{ }^{\circ} \mathrm{C}$ as expected, but the rate eventually slows down such that the final conversion reached is lower than at $75^{\circ} \mathrm{C}$. The decrease in polymerization rate at $90^{\circ} \mathrm{C}$ is not due to the lack of initiator, as there is still $25 \%$ remaining after $16 \mathrm{~h}$ [37]. Thus, the conversion profiles support the hypothesis that depropagation is affecting SHMeMB polymerization, consistent with the observation of increased AM incorporation into the SHMeMB:AM copolymer observed at elevated temperatures.

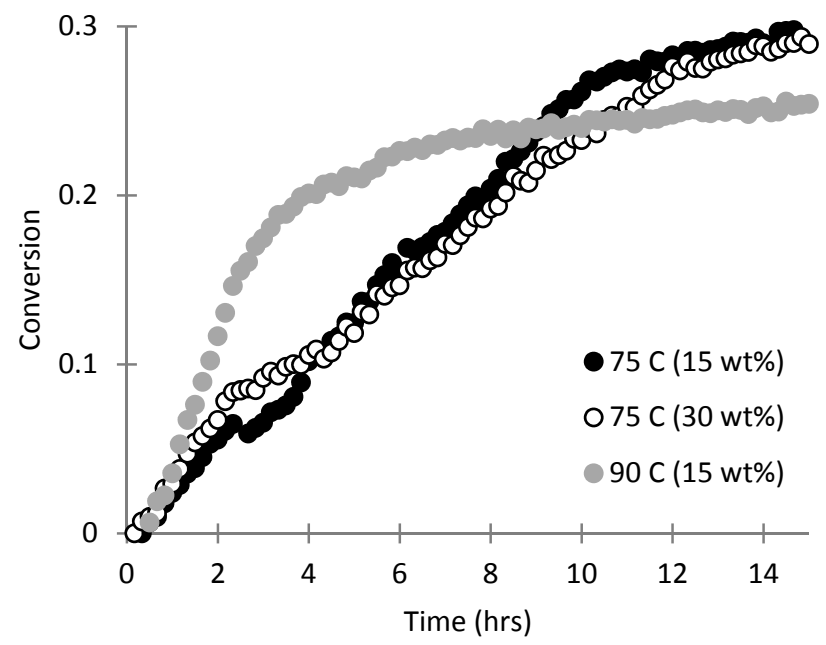

Figure 4. Monomer conversion profiles obtained by homopolymerization of SHMeMB at 15 and $30 \mathrm{wt} \%$ at $75^{\circ} \mathrm{C}$ and $1 \mathrm{wt} \% \mathrm{~V}-86$, and at $15 \mathrm{wt} \%$ and $90{ }^{\circ} \mathrm{C}$.

It was previously demonstrated that the polymerization rate of fully ionized acrylic acid was influenced by the addition of a salt, such that at a molar ratio of 1:5.7 [ $\left.\mathrm{AA}^{-}\right]:[\mathrm{NaCl}]$ the polymerization rate of fully ionized AA (NaAA) was comparable to that of non-ionized AA [31]. It was proposed that the screening of charges by the added salt reduced the repulsion between the ionized monomers and ionized radical sites, therefore enhancing the polymerization rate of fully-ionized AA. Thus, $\mathrm{NaCl}$ was added to SHMeMB homopolymerizations to examine for a similar effect, as shown in Figure 5. The polymerization rate at $75{ }^{\circ} \mathrm{C}$ was found to decrease with added salt, with the rate of polymerization perhaps slightly lower at the 1:1 ratio of SHMeMB]:[NaCl] compared to the 1:0.5 ratio.

Although the rate of monomer conversion of NaAA was increased by increasing ionic strength [31], a similar increase was not observed for NaMAA [17]. However, a separate study showed that the $k_{\mathrm{p}}$ of NaMAA did increase with ionic strength [32]. Therefore, it can be concluded that $k_{\mathrm{p}}$ and $k_{\mathrm{t}}$ for ionized monomers are both affected (increased) by the presence of salt, but to different extents, according to the monomer. Individual estimates are not available for SHMeMB, but the conversion profiles in Figure $5 \mathrm{a}$ indicate that $k_{\mathrm{t}}$ is enhanced in the presence of $\mathrm{NaCl}$ to a greater extent than $k_{\mathrm{p}}$, hence decreasing the overall rate of polymerization at $75^{\circ} \mathrm{C}$. As shown in Figure $5 \mathrm{~b}$, the addition of $\mathrm{NaCl}$ to the polymerization at $90^{\circ} \mathrm{C}$, however, has no effect on the conversion profile. Depropagation 
is more important at this elevated temperature, complicating the situation; however, the net effect of the added salt on the rate of conversion is minor.
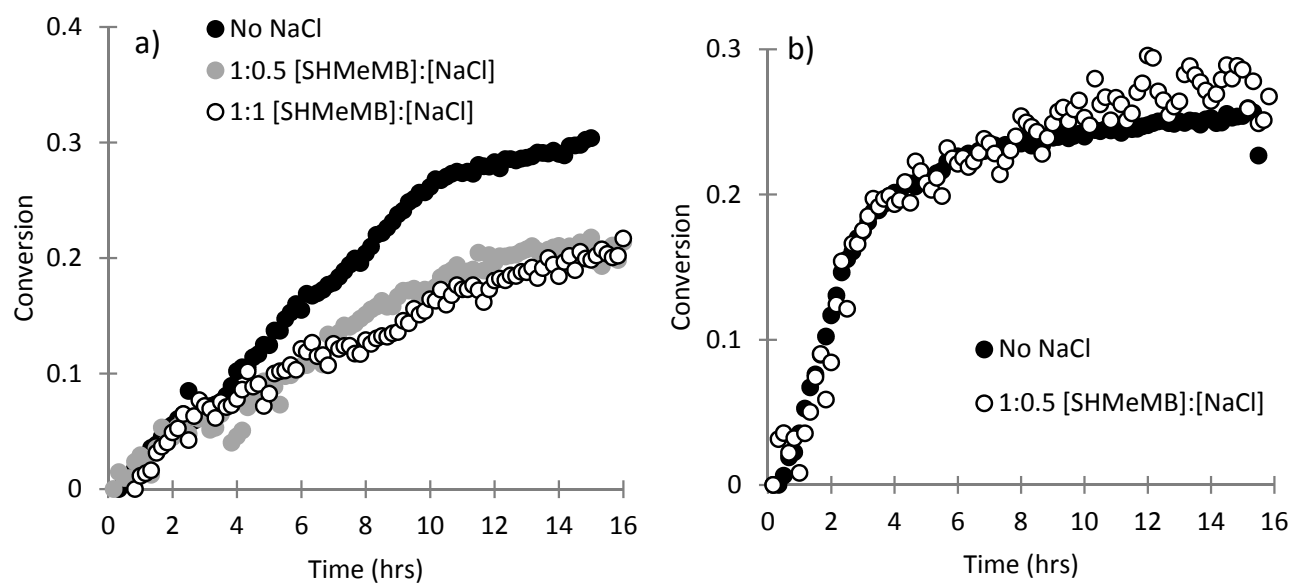

Figure 5. Monomer conversion profiles obtained from homopolymerizations of SHMeMB at 15 wt \% with (a) added $\mathrm{NaCl}$ salt at $75{ }^{\circ} \mathrm{C}$ and 1 wt \% V-86, and (b) at $90{ }^{\circ} \mathrm{C}$ with added $\mathrm{NaCl}$ at 1:0.5 [SHMeMB]:[NaCl] molar ratio.

\subsection{Parameter Estimation for SHMeMB Homopolymerizations}

The SHMeMB homopolymerization conversion profiles presented in Section 3.2 are used in this section to estimate both the termination $\left(k_{\mathrm{t}}\right)$ and depropagation $\left(k_{\mathrm{dep}}\right)$ coefficients using the data-fitting tools in PREDICI based on the mechanisms shown in Table 1 (initiation, propagation, depropagation and termination). As conversion profiles are a function of the ratios of rate coefficients $\left(k_{\mathrm{dep}} / k_{\mathrm{p}}\right.$ and $\left.k_{\mathrm{p}} / k_{\mathrm{t}}{ }^{0.5}\right)$, the strategy employed was to use the previously-estimated propagation coefficient $\left(k_{\mathrm{p}}\right)$ of SHMeMB from the PLP-SEC study [12], and to estimate $k_{\text {dep }}$ simultaneously with $k_{\mathrm{t}}$. For simplicity, the $k_{\mathrm{p}}$ value of $25 \mathrm{~L} \cdot \mathrm{mol}^{-1} \cdot \mathrm{s}^{-1}$ estimated at $60{ }^{\circ} \mathrm{C}$ was used, as the activation energy for propagation is not known. Thus, the estimates for $k_{\mathrm{t}}$ and $k_{\mathrm{dep}}$ at 75 and $90^{\circ} \mathrm{C}$ are lower than the true values, but could be corrected once the temperature dependency of $k_{\mathrm{p}}$ is determined.

The initial fitting of the SHMeMB homopolymerizations curves, shown in Figure 6, was conducted assuming no depropagation occurs $\left(k_{\mathrm{dep}}=0\right)$. The model fits the experimental data reasonably well at $75{ }^{\circ} \mathrm{C}$ until the point at which the rate of polymerization seemed to decrease, around $10 \mathrm{~h}$ into the reaction. However, it is evident that the model with no depropagation was not sufficient in fitting the experiment conversion profile at $90^{\circ} \mathrm{C}$, predicting a continued increase in conversion not observed experimentally. The best fit value of $k_{\mathrm{t}}$ is $1.3 \times 10^{6} \mathrm{~L} \cdot \mathrm{mol}^{-1} \cdot \mathrm{s}^{-1}$ at both 75 and $90^{\circ} \mathrm{C}$, although the true values would be lower (due to the assumption that depropagation does not occur). Furthermore, $k_{\mathrm{t}}$ does not seem to be a large function of temperature, as the same value was able to fit the initial polymerization rate for both 75 and $90{ }^{\circ} \mathrm{C}$. These estimates of $k_{\mathrm{t}}$ are higher than recently reported values for NaAA of $\sim 10^{5} \mathrm{~L} \cdot \mathrm{mol}^{-1} \cdot \mathrm{s}^{-1}$ [38]. 

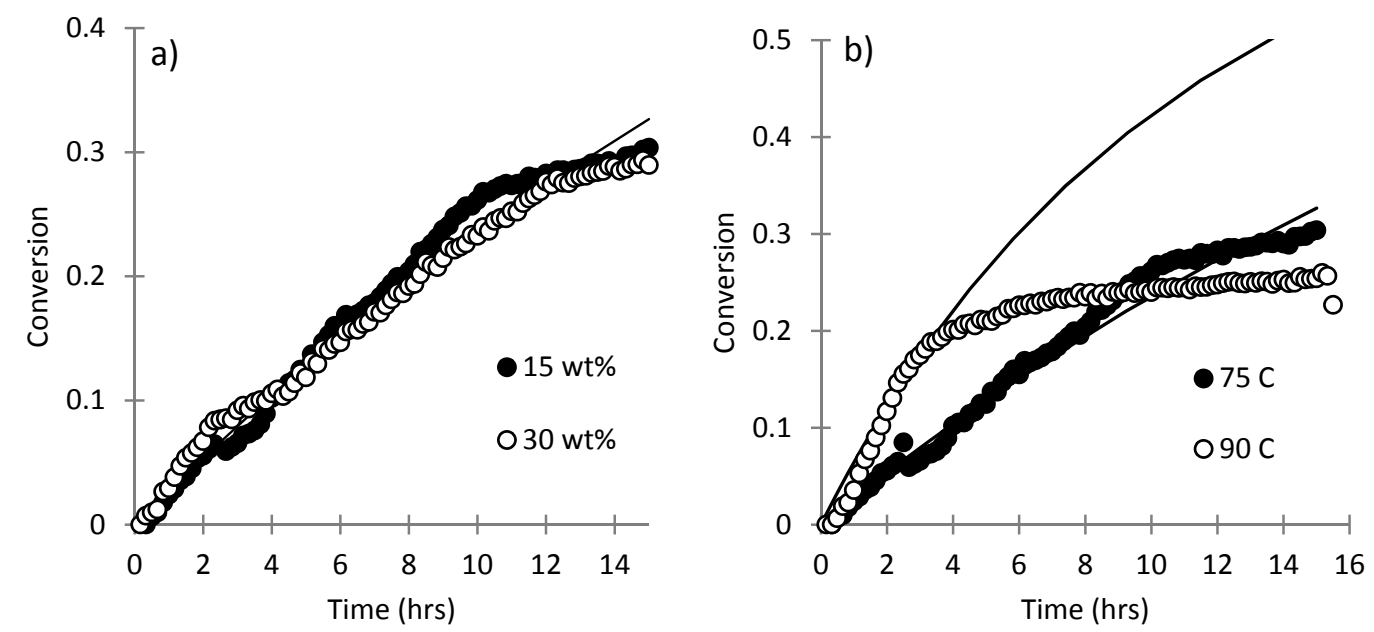

Figure 6. Fit of the homopolymerization SHMeMB model assuming no depropagation to monomer conversion profiles obtained at (a) $75{ }^{\circ} \mathrm{C}$ with 1 wt \% V-86 at different monomer concentrations, and (b) at different temperatures with $1 \mathrm{wt} \% \mathrm{~V}-86$ and $15 \mathrm{wt} \%$ monomer. Solid lines represent model output, with experimental results indicated by data points.

The experimental conversion profile of SHMeMB hompolymerization at $75{ }^{\circ} \mathrm{C}$ was converted using the integrated conversion equation for a batch isothermal reaction, Equation (3), to generate a $k_{\mathrm{p}} / k_{\mathrm{t}}{ }^{0.5}$ vs. conversion plot. In Equation (3), $X$ represents conversion, $k_{\mathrm{d}}$ is the decomposition rate coefficient of V-86 initiator, $t$ is reaction time, $[I]_{0}$ is initial initiator concentration, and $f$ is initiator efficiency.

$$
\frac{k_{p}}{k_{t}^{0.5}}=\frac{\ln (1-X)}{\exp \left(0.5 k_{d} t\right)-1} \sqrt{\frac{k_{d}}{8[I]_{0} f}}
$$

Note that Equation (3) is derived assuming that both $k_{\mathrm{p}}$ and $k_{\mathrm{t}}$ are constant with conversion, and that depropagation does not occur in the system. In general, the $k_{\mathrm{p}} / k_{\mathrm{t}}{ }^{0.5}$ ratio calculated from the experimental data at $75{ }^{\circ} \mathrm{C}$, as shown in Figure 7 , is fairly constant until it reaches a conversion of $25 \%$, at which point it starts to decrease, likely due to the influence of depropagation. (The $k_{\mathrm{p}} / k_{\mathrm{t}}^{0.5}$ values at $<10 \%$ conversion were omitted due to scatter of experimental data in the initial stages of the reaction.) Assuming that depropagation was negligible between 0 and $25 \%$ conversion and a $k_{\mathrm{p}}$ value of $25 \mathrm{~L} \cdot \mathrm{mol}^{-1} \cdot \mathrm{s}^{-1}$, the average value of $k_{\mathrm{p}} / k_{\mathrm{t}}{ }^{0.5}$ of $0.022\left(\mathrm{~L} \cdot \mathrm{mol}^{-1} \cdot \mathrm{s}^{-1}\right)^{0.5}$ in this region is used to estimate a value of $k_{\mathrm{t}}$ of $1.30 \times 10^{6} \mathrm{~L} \cdot \mathrm{mol}^{-1} \cdot \mathrm{s}^{-1}$, in agreement with the value fit to generate the conversion profiles in Figure 6. Also in agreement with Figure 6, the $k_{\mathrm{p}} / k_{\mathrm{t}}^{0.5}$ ratio begins to decrease at a lower conversion at $90^{\circ} \mathrm{C}$, leading to the overestimation of the reaction rate without the consideration of depropagation.

The $k_{\mathrm{t}}$ value of $1.30 \times 10^{6} \mathrm{~L} \cdot \mathrm{mol}^{-1} \cdot \mathrm{s}^{-1}$ was estimated using the $k_{\mathrm{p}} / k_{\mathrm{t}}^{0.5}$ equation assuming depropagation was negligible in the early stages of the reaction, but the true extent of depropagation is still unknown at 75 and $90{ }^{\circ} \mathrm{C}$. Using parameter estimation on PREDICI, both $k_{\mathrm{t}}$ and $k_{\mathrm{dep}}$ values were simultaneously estimated to be $1.4 \pm 1.8 \times 10^{5} \mathrm{~L} \cdot \mathrm{mol}^{-1} \cdot \mathrm{s}^{-1}$ and $21 \pm 6 \mathrm{~s}^{-1}$, respectively, at $75^{\circ} \mathrm{C}$. The estimated value $k_{\mathrm{t}}$ is an order of magnitude lower than estimated using the $k_{\mathrm{p}} / k_{\mathrm{t}}^{0.5}$ plot, but is in reasonable agreement with reported estimates for other ionized monomers [33]. However, the $95 \%$ confidence interval encompasses zero, due to the difficulty in estimating both $k_{\mathrm{t}}$ and $k_{\mathrm{dep}}$ from a single conversion profile. Thus, the strategy taken was to fix $k_{\mathrm{t}}$ at the value of $1.4 \times 10^{5} \mathrm{~L} \cdot \mathrm{mol}^{-1} \cdot \mathrm{s}^{-1}$, and estimate only the $k_{\text {dep }}$ values from the conversion profiles obtained with $15 \mathrm{wt} \%$ SHMeMB at both 75 and $90{ }^{\circ} \mathrm{C}$. The resulting fits to the conversion profiles are shown in Figure 8, with best fit values for $k_{\text {dep }}$ of $20.9 \pm 0.6$ and $26.8 \pm 0.4 \mathrm{~s}^{-1}$ at 75 and $90^{\circ} \mathrm{C}$, respectively. The best fit profiles are compared to the curves generated assuming no depropagation (at $75{ }^{\circ} \mathrm{C}$ extended to longer time), to further 
illustrate that the higher $k_{\mathrm{t}}$ value estimated from the $k_{\mathrm{p}} / k_{\mathrm{t}}{ }^{0.5}$ plot did not adequately represent the shape of the curve. Although the estimation at $90{ }^{\circ} \mathrm{C}$ did not fit as well to the experimental data, the higher estimated value of $k_{\text {dep }}$ indicates that, as expected, depropagation is enhanced at elevated temperatures. Furthermore, the fitting indicates an SHMeMB ceiling temperature (at a standard state of $1 \mathrm{~mol} \cdot \mathrm{L}^{-1}$ ) of about $90^{\circ} \mathrm{C}$, at which point $k_{\mathrm{p}}$ and $k_{\text {dep }}$ estimates are almost identical. It is interesting to note that this value is close to the ceiling temperature of $83^{\circ} \mathrm{C}$ reported for MVL [30], although the latter was polymerized in a closed ring form in organic solvent.

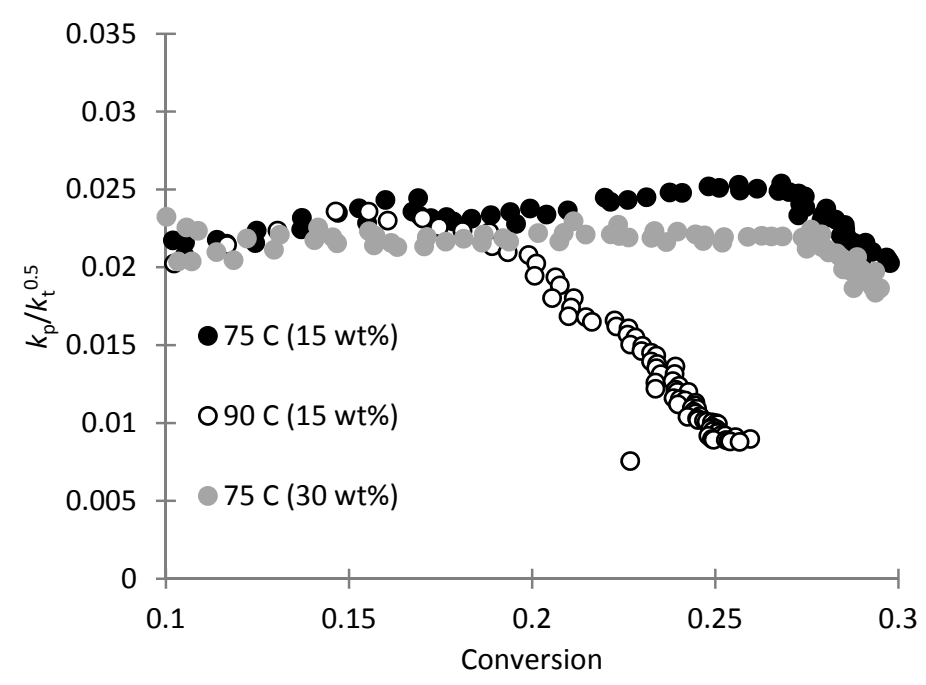

Figure 7. $k_{\mathrm{p}} / k_{\mathrm{t}}{ }^{0.5}$ vs. conversion profile of SHMeMB homopolymerization at $75^{\circ} \mathrm{C}$ with 15 and 30 wt $\%$ monomer concentration and at $90{ }^{\circ} \mathrm{C}$ with $15 \mathrm{wt} \%$ monomer and $1 \mathrm{wt} \% \mathrm{~V}-86$ for $15 \mathrm{~h}$.
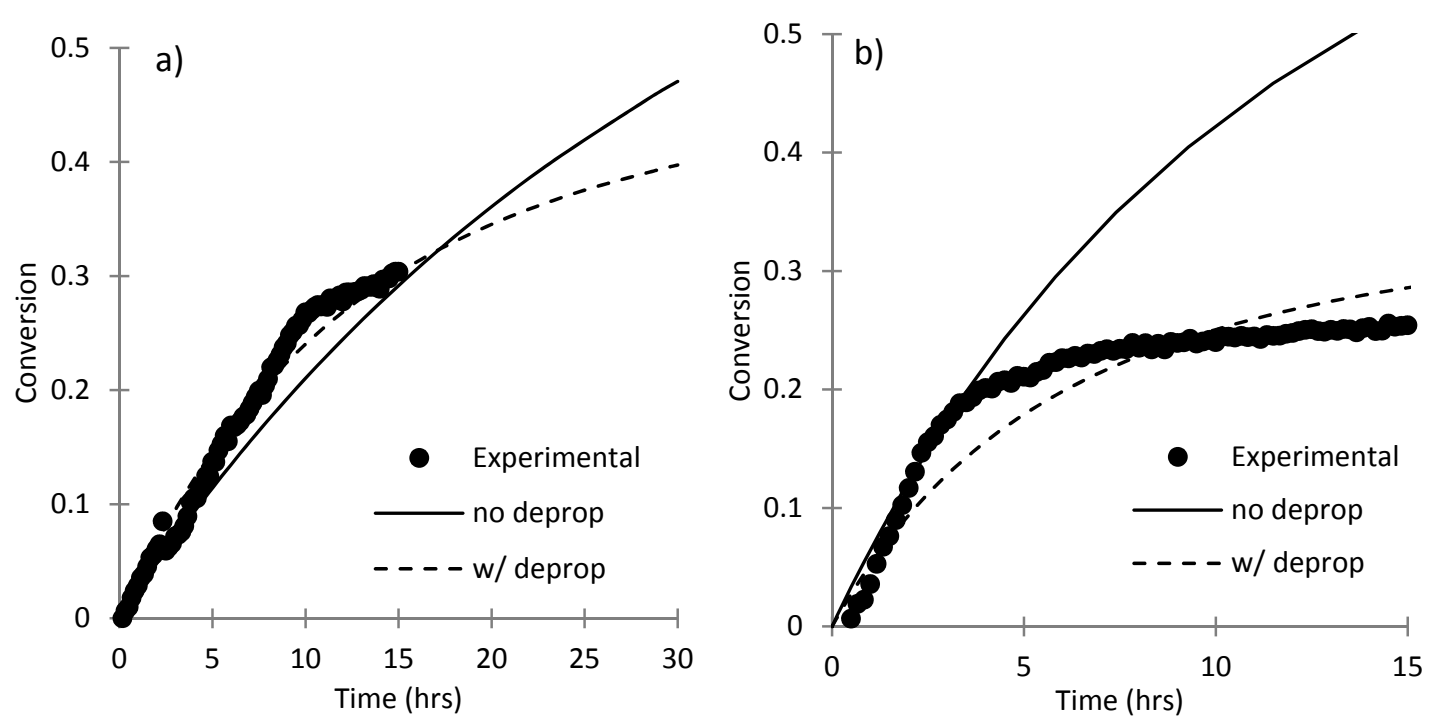

Figure 8. Conversion profile of SHMeMB homopolymerization with 15 wt \% monomer and 1 wt $\%$ $\mathrm{V}-86$ at (a) $75{ }^{\circ} \mathrm{C}$ and (b) at $90{ }^{\circ} \mathrm{C}$. Lines indicate best-fit simulation results with (- - - ) and without $(-)$ depropagation.

Termination and depropagation rate coefficients were also estimated at the higher monomer concentration conditions of $30 \mathrm{wt} \% \mathrm{SHMeMB}$ at $75{ }^{\circ} \mathrm{C}$ with $1 \mathrm{wt} \% \mathrm{~V}-86$. From previous PLP-SEC studies [39], $k_{\mathrm{p}}{ }^{\text {cop }}$ of $10 \mathrm{~mol} \%$ SHMeMB in SHMeMB:AM mixtures at 10 and $20 \mathrm{wt} \%$ were within experimental error. Therefore, a $k_{\mathrm{p}}$ value of $25 \mathrm{~L} \cdot \mathrm{mol}^{-1} \cdot \mathrm{s}^{-1}$ was also assumed for SHMeMB homopolymerization at $30 \mathrm{wt} \%$. The value of $k_{\mathrm{dep}}$ was also kept constant, and the conversion profile 
used to estimate a $k_{\mathrm{t}}$ value of $6.15 \pm 0.02 \times 10^{5} \mathrm{~L} \cdot \mathrm{mol}^{-1} \cdot \mathrm{s}^{-1}$, with the fitted curve compared to the experimental conversion profile in Figure 9. Even though the observed conversion profiles at 15 and $30 \mathrm{wt} \%$ were nearly identical, the estimated values for $k_{\mathrm{t}}$ increased significantly, a finding consistent with a previous study that showed that the $k_{\mathrm{t}}$ of fully ionized NaMAA increased with monomer concentration [40].

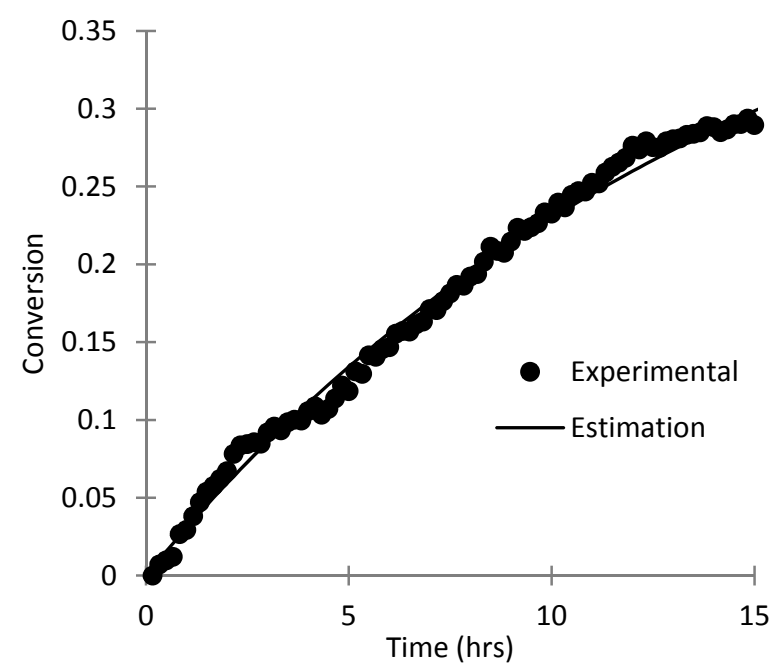

Figure 9. Monomer conversion profiles for the homopolymerization of SHMeMB at $75{ }^{\circ} \mathrm{C}$ with $1 \mathrm{wt} \% \mathrm{~V}-86$ and $30 \mathrm{wt} \%$ monomer. The solid line represents the estimated conversion profile using parameter estimation.

Finally, parameter estimations were also done for the homopolymerizations of SHMeMB with added $\mathrm{NaCl}$ at $75{ }^{\circ} \mathrm{C}$. While depropagation is generally attributed to the steric hindrance near the $\alpha$-carbon, it is possible that electrostatic repulsion from the ionized carboxylic groups can also affect the mechanism. Nonetheless, it was assumed that $k_{\text {dep }}$ remains the same with added salt $\left(21 \mathrm{~s}^{-1}\right.$ as determined previously), as the first order depropagation mechanism is less likely to be influenced by the reaction environment than the bimolecular termination and propagation reactions and, as previously stated, both the $k_{\mathrm{p}}$ and $k_{\mathrm{t}}$ values for polymerizations of fully ionized monomers with added salt have been observed to increase with ionic strength [32]. The estimated conversion profiles are compared to the experimental results in Figure 10. As expected, the estimated values for $k_{\mathrm{p}}$ and $k_{\mathrm{t}}$ summarized in Table 4 have high uncertainty due to the difficulty of estimating two rate coefficients from the same conversion profile, with $95 \%$ confidence intervals encompassing zero. However, the best fit values are roughly the same for both 1:0.5 and 1:1 molar ratios of [SHMeMB]:[NaCl]. While the estimated values for $k_{\mathrm{p}}$ did not increase greatly with the addition of salt (from 25 to $\sim 30 \mathrm{~L} \cdot \mathrm{mol}^{-1} \cdot \mathrm{s}^{-1}$ ), the estimates for the $k_{\mathrm{t}}$ values increased an order of magnitude to $1 \times 10^{6} \mathrm{~L} \cdot \mathrm{mol}^{-1} \cdot \mathrm{s}^{-1}$, significantly larger than the value of $1 \times 10^{5} \mathrm{~L} \cdot \mathrm{mol}^{-1} \cdot \mathrm{s}^{-1}$ estimated without salt. Although estimated with high uncertainty, it is interesting to note that this increase in $k_{\mathrm{t}}$ is consistent with the increase estimated for the $30 \mathrm{wt} \% \mathrm{SHMeMB}$ homopolymerization, suggesting that charge screening provided from either the higher SHMeMB monomer concentration or added salt lowers the electrostatic barrier to radical-radical termination. 
Table 4. Estimated values for $k_{\mathrm{p}}$ and $k_{\mathrm{t}}$ for homopolymerizations of SHMeMB with added salt at $75^{\circ} \mathrm{C}$ with $1 \mathrm{wt} \% \mathrm{~V}-86$ and $15 \mathrm{wt} \%$ monomer assuming a $k_{\text {dep }}$ value of $21 \mathrm{~s}^{-1}$. Results are shown for reactions done with 1:0.5 and 1:1 molar ratios of [SHMeMB]:[NaCl].

\begin{tabular}{ccccc}
\hline & \multicolumn{2}{c}{$\mathbf{1 : 0 . 5}[\mathrm{SHMeMB}]:[\mathrm{NaCl}]$} & \multicolumn{2}{c}{$\mathbf{1 : 1}[\mathrm{SHMeMB}]:[\mathrm{NaCl}]$} \\
\hline & & $\mathbf{9 5 \%}$ Confidence & & $\mathbf{9 5 \%}$ Confidence \\
$\boldsymbol{k}_{\mathrm{p}}\left(\mathbf{L} \cdot \mathbf{m o l}^{-\mathbf{1}} \cdot \mathbf{s}^{-\mathbf{1}}\right)$ & 30.3 & \pm 50.9 & 29.2 & \pm 37.0 \\
$\boldsymbol{k}_{\mathrm{t}}\left(\mathbf{L} \cdot \mathbf{m o l}^{\mathbf{- 1}} \cdot \mathbf{s}^{\mathbf{- 1}}\right)$ & $9.98 \times 10^{5}$ & $\pm 7.96 \times 10^{6}$ & $1.01 \times 10^{6}$ & $\pm 6.32 \times 10^{6}$ \\
\hline
\end{tabular}

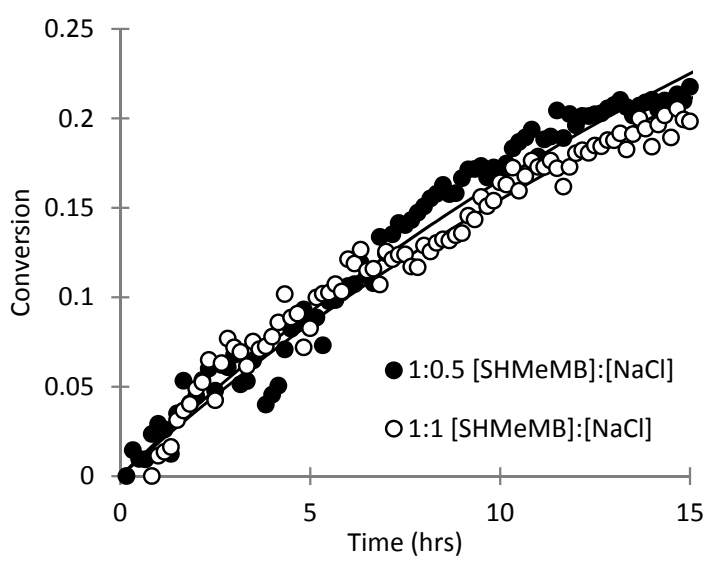

Figure 10. Monomer conversion profiles from homopolymerization of SHMeMB with different concentrations of added $\mathrm{NaCl}$ salt at $75{ }^{\circ} \mathrm{C}$ with $1 \mathrm{wt} \% \mathrm{~V}-86$ and $15 \mathrm{wt} \%$ monomer. The solid lines represent the simulated conversion profiles using parameter estimation.

To summarize, despite considerable uncertainty in the parameter estimations, the analysis of the SHMeMB homopolymerization conversion profiles suggests that the system is characterized by similar $k_{\mathrm{t}}$ values to other ionized monomers, but has very low propagation rates and significant depropagation. A large increase in $k_{\mathrm{t}}$ was required to fit the conversion profiles measured with added salt and with increased monomer concentration, consistent with trends observed in NaMAA [40].

\subsection{Parameter Estimation for SHMeMB:AM Copolymerizations with Depropagation}

The knowledge gained regarding the kinetic behavior of SHMeMB is here applied to the interpretation of the experimental SHMeMB:AM copolymerizations. Details of the PREDICI model, which assumes terminal chain-growth kinetics and SHMeMB depropagation, and uses a single $k_{\mathrm{t}}$ value to represent termination in the two-monomer system, is presented in Section 2.4. Using the coefficients at $50{ }^{\circ} \mathrm{C}$ summarized in Table 2, and a SHMeMB $k_{\text {dep }}$ value of $21 \mathrm{~s}^{-1}, k_{\mathrm{t}}$, values of the copolymerization system were estimated at $50{ }^{\circ} \mathrm{C}$ for the different molar ratios of SHMeMB and AM studied experimentally. The estimated $k_{\mathrm{t}}$ values of SHMeMB:AM copolymers are plotted as a function of $f_{\mathrm{SHMeMB}}$ in Figure 11, with $k_{\mathrm{t}, \mathrm{AM}}$ and $k_{\mathrm{t}, \mathrm{SHMeMB}}$ included for reference. The termination rate coefficient for $\mathrm{AM}\left(k_{\mathrm{t}, \mathrm{AM}}\right)$ was reported as a function of monomer concentration and temperature [20,41]. At $50{ }^{\circ} \mathrm{C}, k_{\mathrm{t}, \mathrm{AM}}$ values at 10 and $20 \mathrm{wt} \%$ were calculated to be $5.2 \times 10^{8}$ and $4.2 \times 10^{8} \mathrm{~L} \cdot \mathrm{mol}^{-1} \cdot \mathrm{s}^{-1}$, respectively. Taking the average of the two values gave an estimate of $k_{\mathrm{t}, \mathrm{AM}}$ of $4.7 \times 10^{8} \mathrm{~L} \cdot \mathrm{mol}^{-1} \cdot \mathrm{s}^{-1}$ for $15 \mathrm{wt} \%$ monomer, several orders of magnitude higher than the $k_{\mathrm{t}}$ of SHMeMB $\left(k_{\mathrm{t}, \mathrm{SHMeMB}}\right)$ estimated as $1.4 \times 10^{5} \mathrm{~L} \cdot \mathrm{mol}^{-1} \cdot \mathrm{s}^{-1}$ at $15 \mathrm{wt} \%$ and $75{ }^{\circ} \mathrm{C}$ in Section 3.4. The fitting of $k_{\mathrm{t}}$ to the SHMeMB:AM copolymerizations at $50{ }^{\circ} \mathrm{C}$ with $0.5 \mathrm{wt} \% \mathrm{~V}-50$ and $15 \mathrm{wt} \%$ monomer provided a very good representation of the experimental conversion profiles, as seen in Figure S3. 


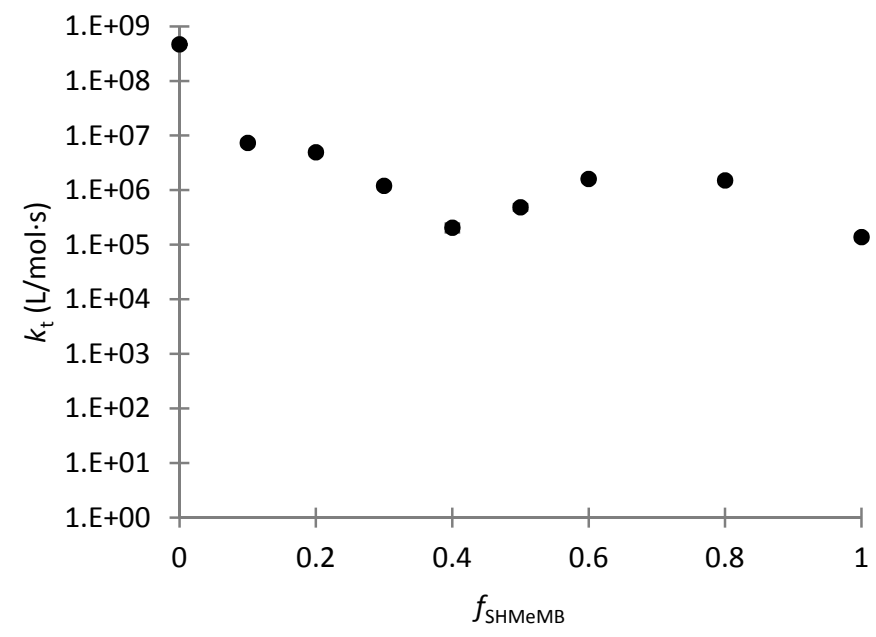

Figure 11. $k_{\mathrm{t}}$ of SHMeMB:AM copolymers estimated for copolymerizations done at $50{ }^{\circ} \mathrm{C}$ with 0.5 wt $\%$ $\mathrm{V}-50$ and 15 wt \% monomer.

Figure 11 shows an immediate drop of two orders of magnitude upon addition of SHMeMB as a comonomer to $\mathrm{AM}$, with values further decreasing to $\sim 10^{5} \mathrm{~L} \cdot \mathrm{mol}^{-1} \cdot \mathrm{s}^{-1}$ as $f_{\mathrm{SHMeMB}}$ increases to 0.4 , at which point the estimates level out. The value of $10^{5} \mathrm{~L} \cdot \mathrm{mol}^{-1} \cdot \mathrm{s}^{-1}$ is similar to the estimated value for $k_{\mathrm{t}, \mathrm{SHM} M \mathrm{MB}}$ in the previous section, and also the value of $3.6 \times 10^{5} \mathrm{~L} \cdot \mathrm{mol}^{-1} \cdot \mathrm{s}^{-1}$ reported for homotermination of NaAA at $20 \mathrm{wt} \%$ and $50{ }^{\circ} \mathrm{C}$ in aqueous solution [38]. Comparable $k_{\mathrm{t}}$ values for SHMeMB and NaAA indicate that the slow termination of two radicals in these systems is dominated by the electrostatic repulsion of the charged species near the radical site, rather than the steric hindrance that leads to the slow propagation and occurrence of depropagation of SHMeMB.

The $k_{\mathrm{t}}$ value estimated for the copolymerization is an averaged value that describes all termination events in the SHMeMB:AM copolymerization, assuming terminal model kinetics. This averaging is described by Equation (4), where $f_{\mathrm{r}, \mathrm{SHMeMB}}$ is the fraction of SHMeMB terminal radicals, $f_{\mathrm{r}, \mathrm{AM}}$ is the fraction of AM terminal radicals, and $k_{\mathrm{t}, \mathrm{SA}}$ is the rate coefficient describing the cross-termination of SHMeMB and AM radicals [28].

$$
k_{t}=k_{t, \text { SHMeMB }} f_{r, S H M e M B}^{2}+2 k_{t, S A} f_{r, S H M e M B} f_{r, A M}+k_{t, A M} f_{r, A M}^{2}
$$

According to Equation (4), $k_{\mathrm{t}}$ must be dominated by the value of $k_{\mathrm{t}, \mathrm{SHMeMB}}$, as its value decreases by two orders of magnitude from the value of $k_{\mathrm{t}, \mathrm{AM}}$ when only $10 \mathrm{~mol} \%$ of SHMeMB is added to the mixture. This large drop indicates that even at a low initial SHMeMB monomer fraction, the fraction of SHMeMB radicals $\left(f_{\mathrm{r}, \mathrm{SHMeMB}}\right)$ is very high. Indeed, given the reactivity ratios of the system and the high homopropagation rate of AM (see Table 2), it can be calculated that at $f_{\mathrm{SHMeMB}}=0.1, f_{\mathrm{r}, \mathrm{SHMeMB}}$ is greater than $99 \%$, such that SHMeMB-SHMeMB termination is the dominant termination event.

\section{Conclusions}

The difference in reactivity between SHMeMB and SHMB [12] motivated these further kinetic studies to explore the effects of depropagation and added salt on the polymerization rate. A plateau in conversion was observed for SHMeMB:AM copolymerizations conducted at 3:7 and 4:6 molar ratios and elevated temperatures, with monomer composition drift occurring at a faster rate as temperature increased and AM incorporated faster as SHMeMB units became more prone to depropagation. Homopolymerizations of SHMeMB at 75 and $90{ }^{\circ} \mathrm{C}$ provided further evidence of depropagation, as conversion reached a lowered equilibrium value at the higher temperature. Upon the addition of salt, the SHMeMB homopolymerization rate decreased at $75^{\circ} \mathrm{C}$, but not at $90^{\circ} \mathrm{C}$, due to the dominating effect of depropagation over the screening of charges provided by counterions. 
The experimental data was fitted to models developed in PREDICI in order to estimate termination $\left(k_{\mathrm{t}}\right)$ and depropagation $\left(k_{\mathrm{dep}}\right)$ rate coefficients for SHMeMB, assuming a constant $k_{\mathrm{p}}$ value of $25 \mathrm{~L} \cdot \mathrm{mol}^{-1} \cdot \mathrm{s}^{-1}$. The $k_{\mathrm{t}}$ values were estimated to be $\sim 10^{5} \mathrm{~L} \cdot \mathrm{mol}^{-1} \cdot \mathrm{s}^{-1}$, similar in magnitude to those reported for NaAA [38] and NaMAA [33], and a ceiling temperature of $\sim 90^{\circ} \mathrm{C}$ was estimated. While these estimates have considerable uncertainty, the modeling effort has provided some valuable insights into the polymerization behavior of the system. The finding that $k_{\mathrm{t}, \mathrm{SHMeMB}}$ is of similar magnitude to other ionic monomers indicates that electrostatic repulsion of charged radical species, rather than steric hindrance from bulky substituents, is the reason for slow termination. The addition of salt and increase in monomer concentration both increased $k_{\mathrm{p}}$ but had a greater effect on the estimated values of $k_{\mathrm{t}}$, showing that addition of salt had a similar effect to an increased concentration of ionized monomers on the polymerization rate. The knowledge gathered from parameter estimations were then implemented to estimate $k_{\mathrm{t}}$ values for SHMeMB:AM copolymerizations, which were found to be much lower than the known value of $10^{8} \mathrm{~L} \cdot \mathrm{mol}^{-1} \cdot \mathrm{s}^{-1}$ for $k_{\mathrm{t}, \mathrm{AM}}$ but similar in magnitude to the estimates of $k_{\mathrm{t}, \mathrm{SHM}} \mathrm{MB}$. This result suggests that $k_{\mathrm{t}}$ in the SHMeMB:AM copolymerization system is largely dominated by $k_{\mathrm{t}, \mathrm{SHM}}$ MB because of the large fraction of charged SHMeMB radicals.

Supplementary Materials: The table and additional figures discussed in the text are available online at www. mdpi.com/2227-9717/5/4/55/s1.

Acknowledgments: The authors would like to thank the Natural Science and Engineering Research Council for their financial support.

Author Contributions: SBL and RAH conceived and designed the experiments; SBL performed the experiments and analyzed the results; SBL and RAH developed the model; SBL performed the parameter estimation; and SBL and RAH wrote the paper.

Conflicts of Interest: The authors declare no conflict of interest.

\section{References}

1. Syed, N.; Habib, W.W.; Kuhajda, A.M. Water-Soluble Polymers in Hair Care. In Water Soluble Polymers; Springer: Boston, MA, USA, 2002; pp. 231-244. ISBN 978-0-306-46915-2.

2. Hayashi, Y.; Lu, D.; Kobayashi, N. Application of Ultra-High Molecular Weight Amphoteric Acrylamide Copolymers to Detergents. In Water Soluble Polymers; Springer: Boston, MA, USA, 2002; pp. 245-250. ISBN 978-0-306-46915-2.

3. Ahmed, E.M. Hydrogel: Preparation, characterization, and applications: A review. J. Adv. Res. 2015, 6, 105-121. [CrossRef] [PubMed]

4. Kadajji, V.; Betageri, G. Water Soluble Polymers for Pharmaceutical Applications. Polymers 2011, 3, $1972-2009$. [CrossRef]

5. Vedoy, D.; Soares, J. Water-soluble polymers for oil sands tailing treatment: A Review. Can. J. Chem. Eng. 2015, 93, 888-904. [CrossRef]

6. Rivas, B.L.; Pereira, E.; Palencia, M.; Sánchez, J. Water-soluble functional polymers in conjunction with membranes to remove pollutant ions from aqueous solutions. Prog. Polm. Sci. 2011, 36, 294-322. [CrossRef]

7. Akkapeddi, M.K. Poly ( $\alpha$-methylene- $\gamma$-butyrolactone) Synthesis Configurational Structure, and Properties. Macromolecules 1979, 12, 546-551. [CrossRef]

8. Suenaga, J.; Sutherlin, D.M.; Stille, J. Polymerization of (RS)-and (R)-a-Methylene-y-methyl-y-butyrolactone. Macromolecules 1984, 17, 2913-2916. [CrossRef]

9. Ueda, M.; Takahashi, M. Radical-initiated homo- and copolymerization of $\alpha$-methylene- $\gamma$-butyrolactone. J. Polym. Sci. 1982, 20, 2819-2828. [CrossRef]

10. Cockburn, R.A.; McKenna, T.F.; Hutchinson, R.A. An Investigation of Free Radical Copolymerization Kinetics of the Bio-renewable Monomer $\gamma$-Methyl- $\alpha$-methylene- $\gamma$-butyrolactone with Methyl methacrylate and Styrene. Macromol. Chem. Phys. 2010, 211, 501-509. [CrossRef]

11. Kollár, J.; Mrlík, M.; Moravčíková, D.; Kroneková, Z.; Liptaj, T.; Lacík, I.; Mosnáček, J. Tulips: A Renewable Source of Monomer for Superabsorbent Hydrogels. Macromolecules 2016, 49, 4047-4056. [CrossRef]

12. Luk, S.B.; Kollár, J.; Chovancová, A.; Mrlík, M.; Lacík, I.; Mosnáček, J.; Hutchinson, R.A. Superabsorbent hydrogels made from bio-derived butyrolactone monomers in aqueous solution. Polym. Chem. 2017. [CrossRef] 
13. Buback, M.; Gilbert, R.G.; Russell, G.T.; Hill, D.J.T.; Moad, G.; O’Driscoll, K.F.; Shen, J.; Winnik, M.A. Consistent values of rate parameters in free radical polymerization systems. II. Outstanding dilemmas and recommendations. J. Polym. Sci. Part A Polym. Chem. 1992, 30, 851-863. [CrossRef]

14. Beuermann, S.; Buback, M.; Hesse, P.; Lacík, I. Free-Radical Propagation Rate Coefficient of Nonionized Methacrylic Acid in Aqueous Solution from Low Monomer Concentrations to Bulk Polymerization. Macromolecules 2006, 39, 184-193. [CrossRef]

15. Lacík, I.; Beuermann, S.; Buback, M. PLP-SEC Study into Free-Radical Propagation Rate of Nonionized Acrylic Acid in Aqueous Solution. Macromolecules 2003, 36, 9355-9363. [CrossRef]

16. Lacík, I.; Beuermann, S.; Buback, M. PLP-SEC Study into the Free-Radical Propagation Rate Coefficients of Partially and Fully Ionized Acrylic Acid in Aqueous Solution. Macromol. Chem. Phys. 2004, 205, 1080-1087. [CrossRef]

17. Lacík, I.; Učňová, L.; Kukučková, S.; Buback, M.; Hesse, P.; Beuermann, S. Propagation Rate Coefficient of Free-Radical Polymerization of Partially and Fully Ionized Methacrylic Acid in Aqueous Solution. Macromolecules 2009, 42, 7753-7761. [CrossRef]

18. Lacík, I.; Chovancová, A.; Uhelska, L.; Preusser, C.; Hutchinson, R.A.; Buback, M. PLP-SEC Studies into the Propagation Rate Coefficient of Acrylamide Radical Polymerization in Aqueous Solution. Macromolecules 2016, 49, 3244-3253. [CrossRef]

19. Kuchta, F.D.; van Herk, A.M.; German, A.L. Propagation Kinetics of Acrylic and Methacrylic Acid in Water and Organic Solvents Studied by Pulsed-Laser Polymerization. Macromolecules 2000, 33, 3641-3649. [CrossRef]

20. Preusser, C.; Chovancová, A.; Lacík, I.; Hutchinson, R.A. Modeling the Radical Batch Homopolymerization of Acrylamide and Aqueous Solution. Macromol. React. Eng. 2016, 10, 490-501. [CrossRef]

21. Preusser, C.; Hutchinson, R.A. An In Situ NMR Study of Radical Copolymerization Kinetics of Acrylamide and Non-Ionized Acrylic Acid in Aqueous Solution. Macromol. Symp. 2013, 333, 122-137. [CrossRef]

22. Preusser, C.; Ezenwajiaku, I.H.; Hutchinson, R.A. The Combined Influence of Monomer Concentration and Ionization on Acrylamide/Acrylic acid Composition in Aqueous Solution Radical Batch Copolymerization. Macromolecules 2016, 49, 4746-4756. [CrossRef]

23. Riahinezhad, M.; McManus, N.; Penlidis, A. Effect of Monomer Concentration and pH on Reaction Kinetics and Copolymer Microsctructure of Acrylamide/Acrylic Acid Copolymer. Macromol. React. Eng. 2015, 9 , 100-113. [CrossRef]

24. Schier, J.E.; Hutchinson, R.A. The influence of hydrogen bonding on radical chain-growth parameters for butyl methacrylate/2-hydroxyethyl acrylate solution copolymerization. Polym. Chem. 2016, 7, 4567-4574. [CrossRef]

25. Li, D.; Li, N.; Hutchinson, R.A. High-Temperature Free Radical Copolymerization of Styrene and Butyl Methacrylate with Depropagation and Penultimate Kinetics Effects. Macromolecules 2006, 39, 4366-4373. [CrossRef]

26. Szablan, Z.; Stenzel, M.H.; Davis, T.P.; Barner, L.; Barner-Kowollik, C. Depropagation Kinetics of Sterically Demanding Monomers: A Pulsed Laser Size Exclusion Chromatography Study. Macromolecules 2005, 38, 5944-5954. [CrossRef]

27. Penelle, J.; Collot, J.; Rufflard, G. Kinetic and thermodynamic analysis of methyl ethacrylate radical polymerization. J. Polym. Sci. 1993, 31, 2407-2412. [CrossRef]

28. Brandrup, J.; Immergut, E.; Grulke, E. Polymer Handbook, 4th ed.; John Wiley \& Sons: New York, NY, USA, 1999; ISBN 978-0-471-47936-9.

29. Morris, L.; Davis, T.; Chaplin, R. Radical copolymerization propagation kinetics of methyl ethacrylate and styrene. Polymer 2001, 42, 941-952. [CrossRef]

30. Ueda, M.; Takahashi, M.; Imai, Y.; Pittman, C.U. Synthesis and homopolymerization kinetics of $\alpha$-methylene- $\delta$-valerolactone, an exo-methylene cyclic monomer with a nonplanar ring system spanning the radical center. Macromolecules 1983, 16, 1300-1305. [CrossRef]

31. Drawe, P.; Buback, M.; Lacík, I. Radical Polymerization of Alkali Acrylates in Aqueous Solution. Macromol. Chem. Phys. 2015, 216, 1333-1340. [CrossRef]

32. Drawe, P. Kinetic of the Radical Polymerization of Ionic Monomers in Aqueous Solution: Spectroscopic Analysis and Modelling. Ph.D. Thesis, University of Göttingen, Göttingen, Germany, 2016. 
33. Barth, J.; Buback, M. SP-PLP-EPR Study into the Termination Kinetics of Methacrylic Acid Radical Polymerization in Aqueous Solution. Macromolecules 2011, 44, 1292-1297. [CrossRef]

34. Wulkow, M. Computer Aided Modeling of Polymer Reaction Engineering-The Status of Predici, 1-Simulation. Macromol. React. Eng. 2008, 2, 461-494. [CrossRef]

35. Wittenburg, N. Kinetics and Modeling of the Radical Polymerization of Acrylic Acid and of Methacrylic Acid in Aqueous Solution. Ph.D. Thesis, University of Göttingen, Göttingen, Germany, 2013.

36. Wako Pure Chemical Industries Ltd. “V-50”. Available online: http://www.wako-chem.co.jp/kaseihin_en/ waterazo/V-50.htm (accessed on 31 March 2017).

37. Wako Pure Chemical Industries Ltd. “VA-086”. Available online: http://www.wako-chem.co.jp/kaseihin en/waterazo/VA-086.htm (accessed on 31 March 2017).

38. Barth, J.; Buback, M. Termination and Transfer Kinetics of Sodium Acrylate Polymerization. Macromolecules 2012, 45, 4152-4157. [CrossRef]

39. Luk, S.B. Radical Polymerization Kinetics of Bio-Renewable Monomers in Aqueous Solution. Master's Thesis, Queen's University, Kingston, ON, Canada, 2017.

40. Kattner, H.; Drawe, P.; Buback, M. Chain-Length-Dependent Termination of Sodium Methacrylate Polymerization in Aqueous Solution Studied by SP-PLP-EPR. Macromolecules 2017, 50, 1386-1393. [CrossRef]

41. Kattner, H.; Buback, M. Termination and Transfer Kinetics of Acrylamide Homopolymerization in Aqueous Solution. Macromolecules 2015, 48, 7410-7419. [CrossRef]

(C) 2017 by the authors. Licensee MDPI, Basel, Switzerland. This article is an open access article distributed under the terms and conditions of the Creative Commons Attribution (CC BY) license (http:// creativecommons.org/licenses/by/4.0/). 